\title{
Prey aggregation is an effective olfactory predator avoidance strategy
}

Predator-prey interactions have a major effect on species abundance and diversity, and aggregation is a well-known anti-predator behaviour. For immobile prey, the effectiveness of aggregation depends on two conditions: (a) the inability of the predator to consume all prey in a group and (b) detection of a single large group not being proportionally easier than that of several small groups. How prey aggregation influences predation rates when visual cues are restricted, such as in turbid water, has not been thoroughly investigated. We carried out foraging (predation) experiments using a fish predator and (dead) chironomid larvae as prey in both laboratory and field settings. In the laboratory, a reduction in visual cue availability (in turbid water) led to a delay in the location of aggregated prey compared to when visual cues were available. Aggregated prey suffered high mortality once discovered, leading to better survival of dispersed prey in the longer term. We attribute this to the inability of the dead prey to take evasive action. In the field (where prey were placed in feeding stations that allowed transmission of olfactory but not visual cues), aggregated (large groups) and semi-dispersed prey survived for longer than dispersed prey - including long term survival. Together, our results indicate that like in systems where predators hunt using vision, aggregation is an effective anti-predator behaviour for prey avoiding olfactory predators. 


\section{Prey aggregation is an effective olfactory predator avoidance strategy}

2

3

4

5 Asa Johannesen ${ }^{1,2}$, Alison M. Dunn ${ }^{2} \&$ Lesley J. Morrell ${ }^{3}$

6

$7 \quad$ Marine Centre, Fiskaaling, við Áir, FO-430 Hvalvík, Faroe Islands

$8 \quad{ }^{2}$ School of Biology, University of Leeds, LS2 9JT

$9 \quad{ }^{3}$ School of Biological, Biomedical and Environmental Sciences, University of Hull, HU6 7RX

11 Correspondence:

12 Marine Centre, Fiskaaling (Aquaculture Research Station of the Faroe Islands), við Áir, FO-430

13 Hvalvík, Faroe Islands

14 asajoh@fiskaaling.fo

$15+298774764$ 
Introduction

Predator-prey interactions are one of the major factors influencing patterns of species

18 diversity and abundance in ecosystems (Chesson and Kuang 2008). Predators influence prey

19 abundance and distribution through both consumptive and non-consumptive effects (Preisser,

20 Orrock, and Schmitz 2007) such as predator avoidance behaviours, which may limit prey access

21 to resources (Griffiths and Richardson 2006). Aggregation into groups is a common response to

22 the risk of predation (Krause and Ruxton 2002). Grouping individuals benefit from the dilution

23 effect if a predator is unable to consume all prey in a group (Foster and Treherne 1981) and from

24 encounter dilution, where aggregated prey are encountered less often assuming population size is

25 kept constant (Wrona and Dixon 1991). Together, this leads to a situation where fewer predators

26 survive because cost of finding a prey group is high, and more prey survive because predators

27 only consume few prey per encounter (Turner and Pitcher 1986; Turesson and Brönmark 2007).

Prey detection is likely to be dependent on a predator's sensory acuity and modality (Cain

30 1985). As a group of prey grows, the ability of a visual predator to detect the group is predicted to

31 increase at a slower rate; that is, a group of $N$ individuals should be less than $N$ times more

32 detectable than a single individual (Brock and Riffenburgh 1960; Treisman 1975; Turner and

33 Pitcher 1986). This is supported by empirical evidence for visual predators, where a non-

34 proportional relationship between prey group size and detection rate has been found for humans

35 seeking computer generated prey (Jackson et al. 2005), sticklebacks (Gasterosteus aculeatus)

36 attacking Daphnia swarms (Ioannou et al. 2011) and great tits (Parus major) searching for

37 aposematic prey (Riipi et al. 2001). 
Whether encounter-dilution effects operate when predators use other sensory modalities is

40 unclear. Close neighbours are likely to produce odour plumes that interact, increasing both the

41 area of the odour plume and the amount of stimulant (Monismith et al. 1990). Treisman (1975)

42 suggests that a group of $N$ individuals should be detectable by an olfactory predator at a distance

$43 \quad N$ times as great as that for a single prey, resulting in an area in which the group can be detected

$44 N^{2}$ times as large as for a single prey (or a volume $N^{3}$ times as large). If this is the case, encounter-

45 dilution would not take place, and grouping would not be favoured unless the predator is highly

46 sensitive to olfactory cues and does not preferentially target large groups over small ones (Cain

47 1985). Recent empirical data indicates that aggregation increases risk of predation by olfactory

48 predators (Whitton et al. 2012; Wilson and Weissburg 2012) but Andersson et al find that the

49 distance at which a group can be detected increases asymptotically with group size (Andersson,

50 Löfstedt, and Hambäck 2013).

While patterns of risk with increasing levels of aggregation are beginning to be

53 established, there is no work that directly contrasts visual and olfactory prey detection rates on

54 dispersed and aggregated prey within the same predator. Changes in the environment, such as

55 fluxes in turbidity or changes in $\mathrm{pH}$, can alter the availability of visual and olfactory information

56 (Leduc et al. 2013). Consequently, these can alter reliance on different sensory modalities by

57 predators (Chapman et al. 2010), which in turn may affect the shape of the interaction between

58 predators and prey. Predators may use both vision and olfaction in detecting prey, increasing

59 reliance on olfaction under poor visual conditions (Chapman et al. 2010). We predicted that the

60 benefits of aggregation as an anti-predator defence would be reduced or eliminated when

61 predators hunt using olfaction rather than vision. To test this prediction, we investigated the

62 ability of sticklebacks (Gasterosteus aculeatus) to detect and consume dispersed and aggregated

63 bloodworm when visual cues were and were not available. Chironomid larvae coexist with 
64 sticklebacks in the wild and are often used as a commercial fish food. The diet of the captive

65 sticklebacks used in this study consisted solely of bloodworm. Sticklebacks are often found in

66 waters that are highly variable in turbidity (Wootton 1976) and employ olfaction to detect prey in

67 turbid water to compensate for the loss of visual cues (Johannesen, Dunn, and Morrell 2012). As

68 a measure of detection, we monitored the survival of prey (frozen and defrosted bloodworm) over

69 time when dispersed and aggregated, and in clear (visual and olfactory cues available) and turbid

70 (no visual cues available) water. Additionally, we tested the effect of three levels of aggregation

71 in the field in order to include more naturally sized foraging settings and multiple predators.

73 Methods

74 (a) Laboratory experiment - does turbidity affect best aggregation strategy?

75 (i) Study species and housing

76 Three spined sticklebacks (36-46 mm total body length) were caught by netting from

77 small water bodies in Saltfleet, Lincolnshire $\left(53^{\circ} 25^{\prime} 59.55^{\prime}\right.$ N, $0^{\circ} 10^{\prime} 49.41^{\prime \prime}$ E) in November 2010

78 and 2011. On both occasions, 250 fish were caught and were transported in commercial fish bags

79 to the aquarium facilities at the University of Leeds. Fish were housed in groups of

80 approximately 50 in grey plastic tubs $(60 \times 90 \times 45 \mathrm{~cm})$ with gravel substrate and artificial plants for

81 environmental enrichment, at $14 \pm 2^{\circ} \mathrm{C}$ and on a 14:10 hour light: dark cycle. Fish were fed $a d$

82 libitum on defrosted frozen bloodworm (chironomid larvae, these were also the prey species in

83 the experiment) from a commercial fish food supplier once daily. Each group of fish was released

84 one year after capture at the location where caught (in agreement with the Home Office and

85 DEFRA).

86

87 (ii) Procedure 
89 Dunn, and Morrell 2012) and is briefly summarized here. We investigated two levels of prey

90 aggregation (aggregated and dispersed) and two levels of water clarity (clear and turbid) in a

91 crossed design, giving 4 treatments (clear-aggregated, clear-dispersed, turbid-aggregated and

92 turbid-dispersed). For logistical reasons, treatments were carried out in a semi-systematic order of

93 blocks of 2-4 experiments of one treatment, followed by a block of another treatment. In each

94 trial, eight designated locations in a foraging arena $(100 \times 100 \mathrm{~cm}$, depth $5 \mathrm{~cm}$, with a $10 \times 10 \mathrm{~cm}$

95 central floating polystyrene shelter) received either one (dead) prey each (dispersed prey) or eight

96 prey in one location (aggregated prey) chosen at random. Each location was a distance of $25 \mathrm{~cm}$

97 from the nearest neighbours and $25 \mathrm{~cm}$ from the arena wall. Turbid water was created by the

98 suspension of commercial clay (Low Temperature White clay from Commercial Clay Ltd) in

99 conditioned water at $0.5 \mathrm{~g} / \mathrm{l}$. Clay is commonly used to create turbidity without ill effects in the

100 study animals (Ferrari, Lysak, and Chivers 2010; Vollset and Bailey 2011). Fish showed no signs

101 of distress in turbid water (gill flares, increased respiration or decreased motivation to feed) and

102 trials lasted no more than 35 minutes. Water was changed between trials to remove olfactory cues

103 from previous fish or prey, and fish were starved for 24 hours before testing to standardize

104 motivation to feed. As our aim was to investigate how prey aggregation affects olfactory prey

105 detection by predators and how survival is affected by prey group size, we chose to use immobile

106 (dead) prey. Mobile prey could produce other cues (e.g. lateral line detection) and potentially

107 benefit from other mechanisms than dilution of risk (e.g. confusion). Testing these other factors

108 was not within the scope of our study.

109

110 Trials were video recorded from above. In each trial a single fish was released under the

111 floating shelter to acclimatize and time to emerge (be fully free of the shelter) was recorded. Fish

112 were only used once and those that did not hide under the shelter on release or did not emerge 
113 within 15 minutes were excluded from the experiment (final sample sizes; clear water and

114 aggregated prey: $\mathrm{N}=13$, clear water and dispersed prey: $\mathrm{N}=15$, turbid water and aggregated

115 prey: $\mathrm{N}=13$, turbid water and dispersed prey: $\mathrm{N}=15$ ). Turbidity in the arena decreased over

116 time, from $391.15 \pm 9.35$ NTU before fish were released to $286.83 \pm 9.1$ NTU after 35 minutes

117 (measured before fish were captured after the trial). To ensure that visibility remained low in

118 turbid water trials, fish were given a maximum of 35 minutes in the foraging arena, consisting of

119 up to 15 minutes before emergence, plus 20 minutes during which foraging was recorded. We

120 assessed the effect of environment (clear/turbid) on time to emergence using a negative binomial

121 GLM to account for overdispersion in the poisson-distributed data. There was no effect of

122 environment on time to emergence $(\mathrm{z}=-1.63, \mathrm{df}=61, \mathrm{P}=0.1)$. This suggests that our manipulation

123 of visual cues did not influence motivation to hunt for prey and/or perceived predation risk of the

124 fish.

125

126

Data on foraging behaviour and time of prey capture for each prey item were manually

extracted from videos using Etholog (2.25) and Windows Media Player. Sticklebacks vary

128 considerably in boldness (Ward et al. 2004; Frost et al. 2007; Harcourt et al. 2010), leading to

129 variation in time spent hiding (and therefore not foraging). Thus, to standardize search time for

130 all fish, we recorded prey capture as a function of time spent actively swimming.

(b) Field experiment: do prey in a more natural setting benefit from aggregating?

133 Our laboratory experiment necessarily constrained the search area available for each

134 predator, increasing the likelihood of chance encounter. Furthermore, it tested the effect of

135 aggregation of prey on survival, but was limited by the small number of prey. As predators were

136 able to consume all prey without reaching satiation, our experiment did not include factors such

137 as the dilution of individual risk (Wrona and Dixon 1991) once discovered. In ponds and lakes, 
138 search volume or area is much greater, and there may be multiple predators (individuals or

139 species) in the environment, affecting how many prey may be consumed and increasing the

140 likelihood of local or stimulus enhancement (where the activity of an individual draws the

141 attention of an observer towards a location or object; (Spence 1937; Thorpe 1956)), or social

142 learning (Brown and Laland 2003). To test the real-world validity of some of our findings, we

143 also carried out a field experiment to assess the survival of visually hidden prey at different levels

144 of aggregation. In order to ensure that cue availability was high enough in these larger water

145 bodies, more prey were used. Because of this, aggregated and semi-dispersed prey groups were

146 large enough to satiate a single predator, thereby allowing for dilution of individual risk within

147 the experiment. The difference in setting and prey number make these two studies

148 complementary rather than directly comparable.

Fieldwork was carried out in fresh to brackish water rock pools on the Faroe Islands,

151 where there is a low diversity of aquatic species, making natural systems much simpler than those

152 in warmer climates (Malmquist et al. 2002; Brodersen et al. 2011). The largest predators in a

153 typical pool above the tidal line are Gammarus duebeni (Roberts 1995) and sometimes three

154 spined sticklebacks (Gasterosteus aculeatus). These ponds also contain a range of invertebrate

155 prey species, including midge larvae which could be found in all ponds included in this

156 experiment. Ponds ( $\mathrm{N}=11)$ were $5-50 \mathrm{~m}^{2}$ in size, all contained sticklebacks, some contained

157 Gammarus, and none connected directly to any other pond in the study. Turbidity in these ponds

158 varies naturally, but was low during our trials (below 10 NTU for all ponds). Visual cues were

159 blocked with the use of "feeding stations" with opaque walls that allowed for transmission of

160 olfactory cues.

161

162 (i) Procedure 
164 feeding station consisted of a weighted transparent cylindrical plastic frame $(12 \mathrm{~cm}$ diameter, 8

165

166

167

168

169

170

171

172

173

174

175

176

177

178

179

180

181

182

184

$\mathrm{cm}$ height) covered in two layers of fine-mesh material (nylon tights, 40 denier) with two entrance holes $(2 \times 2 \mathrm{~cm})$ positioned at opposite sides of the station (Figure 1). The stations were constructed in this way to allow olfactory cues to pass through the sides of the stations freely (pilot experiments in the lab with food dye indicated that cues passed through the walls). Cue movement is extremely slow in still water (Webster and Weissburg 2009), but movement of fish and the disturbance caused by the experimenter moving the station to count prey enhanced cue dispersal. Disturbance was equal across all feeding stations (see below). In each pond, we placed 6 stations close to the edge $(10-30 \mathrm{~cm}$, to allow access by the experimenter), approximately $1 \mathrm{~m}$ apart. Stations were added 2-4 days prior to the first observation day to counter any effects of neophilia or neophobia (Frost et al. 2007; Archard and Braithwaite 2011). To reduce disturbance, feeding stations were left in the ponds for the duration of the trials.

In each pond, we investigated three levels of prey aggregation: (1) aggregated where 30 prey were placed in one of the 6 feeding stations while the remaining 5 stations remained empty (2) semi-dispersed with 10 prey in each of 3 of the 6 stations and 3 empty stations, and (3) dispersed prey where we placed 5 prey in each of the 6 stations. Aggregated prey were allocated to a feeding station at random and semi-dispersed prey were allocated to alternating feeding stations (starting point chosen at random). The order in which the treatments were placed in each pond was systematically rotated ensuring each possible trial sequence was included at least once and no more than twice. To minimize any possible effects of learning and to reduce disturbance, a minimum of 4 days was left between each trial within a pond. Prey used in these trials were frozen bloodworm sourced from a local pet shop. The bloodworm were defrosted and the refrozen in tap water ice cubes in the prey groups sizes above for ease of handling in the field. 
189 On the day of each trial, the ice cubes containing prey were positioned in their allocated

190 feeding stations. Plain ice cubes (containing no prey) were placed in all other stations to control

191 for the presence of the observer at each station and any cues from the tap water that may have

192 been used by potential predators. After 10, 20, 30, 40, 50, 70 and 90 minutes, the observer

193 returned to the pool and counted the number of uneaten prey in each station. Stations containing

194 no prey were also checked to control for the presence of the observer and the disturbance caused

195 by removing and replacing the feeding station. The timer was stopped when the observer returned

196 to the pool, and restarted when counting was complete (approximately 10 minutes), so that the

197 time while disturbed by researcher was not included in the time available to the fish to forage in

198 the stations. It is likely that the presence of the observer disrupted normal foraging behaviour, so

199 care was taken to ensure that this disruption was equal for all treatment groups. However, it is

200 likely that detection would be faster than our data suggests due to this disruption. For this reason,

201 we do not presume to make any claims about absolute detection times, but rather relative

202 differences between prey group sizes in this study.

203

204

(c) Analysis

All data analysis was carried out in R v 2.13.0 (R Core Team 2013). For the laboratory data, prey within a trial were not independent of one another. To account for this, we created multiple events (each predator could consume multiple prey 'events') models using the

208 Andersen-Gill version of Cox Proportional Hazards models in the package 'survival' (Therneau

209 and Grambsch 2000; Therneau and Lumley 2011). Using this method, each prey item is

210 considered an observation (whether consumed or not) leading to model sample sizes referring to

211 individual prey items (8 per trial) rather than the predator or trial numbers. By clustering on 'trial' 
212 (this is akin to adding a random effect), we include in the model that individual prey within trials

213 are not independent.

214

215 Our initial analysis of the laboratory data using a Cox Proportional Hazards model did not

216 meet the necessary assumption of proportional hazards (Chi-squared $=85.6, \mathrm{P}<0.001$; (Therneau

217 and Grambsch 2000)). When this assumption is violated, it is an indication that the survival

218 curves are not the same shape and do not follow similar hazards distributions (i.e. the risk to a

219 prey individual in one treatment is not a simple multiplication of the risk in another treatment, for

220 any given time point). This is especially problematic when survival curves cross as they do in our

221 case; figure 2 (Therneau and Grambsch 2000). In order to remedy this, we split our data set in

222 two ("initial prey discovery" and "subsequent survival of prey") and analyzed these separately

223 (figure 3). The assumption of proportional hazards was met in the case of initial prey discovery

224 (Chi-squared $=3.27, \mathrm{P}=0.351$ ). In the case of subsequent prey discovery, the assumption of

225 proportional hazards was not met (Chi-squared=176.4, $\mathrm{P}<0.001)$. However, survival curves did

226 not cross (figure 2b), so although predictions based on this model should be treated with caution

227 (Therneau and Grambsch 2000), it does give an indication of whether the survival of prey

228 differed between treatments. Here, we use the term 'survival' in the context of survival analysis,

229 where a prey individual 'survives' if it avoids being consumed by a predator (in reality, all prey in

230 our experiments are already dead).

231

232

The data from field trials were interval censored, meaning the exact time of each prey

233 being eaten was not known. Times were defined as the start and stop time of the interval in which

234 prey were eaten, and we fitted a non-parametric maximum likelihood estimate (NPMLE) of the

235 survival distribution (Turnbull 1976). Hypothesis testing was performed using a non-parametric 
236 logrank test, using the packages 'interval' and 'icens' developed for analyzing interval censored

237 data (Fay and Shaw 2010; Gentleman and Vandal 2011). Sun's scores (Sun 1996) indicate the

238 differences and direction of difference between groups, and are chosen for analysis as they are

239 flexible with respect to the duration between interval censored events and are the default option

240 in the 'interval' package for this reason (Fay and Shaw 2010).

241

242

(d) Ethical statement

243

As experiments with fish fall outside of the remit of the University of Leeds Ethical Board

244 and no licensed procedures were used, this study was not subject to ethical review.

245 However, laboratory experiments were carried out in accordance with University of Leeds

246 guidelines and in agreement with Home Office licensed technical staff at the animal facility.

247 Similarly, field experiments were carried out in accordance with local laws and regulations. Great

248 care was taken to ensure optimal welfare for all fish involved in this study.

249

250 Results

251

(a) Laboratory experiment - does turbidity affect best aggregation strategy?

252

253

The survival curve for aggregated prey in turbid water showed a very different pattern to

254 the survival curve for other treatment groups (figure 2). The assumption proportional hazards was

255 not met (Chi-squared=85.6, $\mathrm{P}<0.001$; see above). This suggests that overall patterns of survival

256 differ significantly as a function of treatment grouping.

257

258 When detection of first and subsequent prey are analyzed separately, it is clear that

259 aggregation is beneficial in increasing the time to initial detection in both clear and turbid water, 
260 but has a greater effect in turbid water. There was a significant interaction between water clarity

261 and level of aggregation $(\mathrm{CoxPH} ; \mathrm{z}=2.24, \mathrm{n}=56, \mathrm{P}=0.025)$ on the time until the first prey was

262 discovered (figure 3a). Dispersed prey are discovered more quickly in turbid water than clear

263 water while aggregated prey are discovered more quickly in clear water than turbid water (figure

$2643 a)$.

265

266

For time to consume subsequent prey, there was also a significant interaction between the

267

water clarity and level of aggregation $(\mathrm{CoxPH}, \mathrm{z}=-3.173, \mathrm{n}=302, \mathrm{P}=0.002)$. Survival is highest

268

for dispersed prey in turbid water, while aggregated prey survive longer in clear water than in

269

turbid water (figure 3b). Therefore, after the discovery of the first prey, aggregation appears to be

270

beneficial in clear water (aggregated prey survive longer in clear water than in turbid water), but

271

not in turbid water (where dispersed prey have higher survival).

272

273

(b) Field experiment: do prey in a more natural setting benefit from aggregating?

In the field experiment, prey in the three levels of aggregation differed significantly in

survival (Nonparametric log-rank test with Sun's scores, Chi-squared=13.16, P=0.001) with

dispersed prey being discovered and consumed the most quickly and little to no difference

277

between aggregated and semi-dispersed prey (Suns' score statistics: dispersed: 42.17, aggregated:

-19.11, semi-dispersed: -23.06).

279

280

\section{Discussion}

The data gathered both in the laboratory and in the field reveal that aggregation as a

282 predator avoidance strategy is effective both for visually conspicuous and concealed prey. 
285 improved survival (i.e. were less likely to be consumed) over dispersed prey in terms of initial 286 detection. However, once an aggregation was detected, the prey did not survive (avoid consumption) for very long. This likely occurred because predators were able to find and

288 consume all the prey in an aggregation after having discovered the first prey, and the dead prey 289 could not take any evasive action in response to the proximity of the predator.

In the natural pond setting, overall survival of aggregated and semi-dispersed prey was

292 higher than that of dispersed prey. Additionally, the rapid decrease in aggregated prey numbers once discovered in the lab was not observed in the field. This lack of sudden mortality post discovery is likely due to the large number of prey satiating the predator and thereby providing dilution of risk.

Due to the necessary differences in design between our field and laboratory experiments comparisons between the field and lab data. between stations, indicating that fish were not clearing out one station and then swimming to the next. The overall poorer survival of dispersed prey compared to semi-dispersed and aggregated

304 prey suggests that aggregation should be an adaptive strategy for species living in water where

305 visual cues are limited or absent as well as where the predator of immediate concern does not use 306 visual cues. 
Aggregation as an anti-predator strategy when the predator does not use visual cues is

309 seen in a number of species such as the sediment dwelling Chironomus riparius larvae, who

310 aggregate in response to predator presence (Rasmussen and Downing 1988) and stream dwelling

311 caddis flies (Rhyacophila vao) that avoid predation by the planarian predator Polycelis coronata

312 by communally pupating on the same stone (Wrona and Dixon 1991). Taylor's (1977) study on

313 southern grasshopper mice found that buried aggregated prey were found less easily than

314 dispersed prey. Our data indicate that aggregation can be beneficial to prey in decreasing risk of

315 detection, but also that aggregation is only truly effective if aggregations are large enough to

316 dilute predation risk once discovered if prey are immobile. In many systems prey are at risk from

317 several species of predators and aggregation in response to one predator may be counter-

318 productive if another predator is present (Long et al. 2007). Showing behavioural flexibility in

319 response to predator presence may be a better strategy than simply aggregating by default

320 (Reimer and Tedengren 1997; Kobak, Kakareko, and Poznańska 2010).

There is evidence in our lab results to suggest that the protection provided by aggregating

323 depends partly on the availability of visual cues as well as the perception of risk in the predator.

324 Once discovered, aggregated prey did not survive for long, but those in clear water survived for

325 longer than those in turbid water. Although time to emergence was not affected by turbidity, we

326 suggest that a perceived risk involved in foraging in clear open water (Abrahams and Kattenfeld

327 1997) and the decreased vigilance resulting from foraging activities (Brown 1999) combined to

328 reduce foraging effort and allowed aggregated prey to survive longer once discovered in clear

329 water than in turbid water.

330

331 In the field, aggregated prey did not experience the accelerated death rate once discovered

332 that they did in the laboratory. There is some indication that benefits to prey depend on size or 
333 number of predators (Brock and Riffenburgh 1960) and sticklebacks are able to learn from visual

334 foraging cues from conspecifics (Webster and Laland 2012), resulting in increased discovery if

335 one stickleback in the group starts consuming prey. However darkness or turbid water should

336 reduce the likelihood of this happening, as initial discovery of prey by one predator would not be

337 observed visually by other predators. Lateral line detection of the movement of conspecifics

338 (Coombs 1999) is likely to be too short-range to be relevant in this context, however the

339 importance of noises generated by foraging might warrant further exploration. In our experiment,

340 prey as well as any predator feeding on them, were concealed in feeding stations, which may

341 have prevented visual social cues from being transmitted to other sticklebacks in the area. Prey

342 groups were also much larger than in the laboratory, which likely prevented individual

343 sticklebacks from consuming all prey. Together, this may have limited the rapid consumption of

344 prey seen in the laboratory.

345

The benefits of aggregation are likely to depend on the sensory abilities of the predator

347 and a predator that is unable to detect prey will approach random search efficiency (Cain 1985).

348 However, a predator that is able to detect the presence of prey and perhaps even an indication of

349 the number of prey should perform better than random by increased search effort, especially if

350 that effort can be focused in the general area surrounding prey. Sticklebacks use both visual and

351 olfactory cues in foraging, and when visual cues are not available, the presence of olfactory cues

352 increases foraging efficiency (Johannesen, Dunn, and Morrell 2012). Therefore, strong cue

353 concentrations around aggregated prey could increase search effort, potentially countering the

354 benefit prey derive from aggregating. Similarly, theory on the relationship between olfactory cues

355 and detection of prey groups predicts that grouping should not be favoured as detection radius

356 increases with group size (Treisman 1975). In our study, however, it is clear that aggregation is

357 beneficial to prey, at least at the predator-prey ratios tested here, as our aggregated prey survived 
358 for longer than the dispersed prey. There is some evidence to suggest that olfactory detection

359 radius increases with group size (Andersson, Löfstedt, and Hambäck 2013), but it is still not clear

360 how increased detection affects aggregated prey in different systems such as one where only one

361 prey item is captured and the rest escape and how predator sensory acuity interacts with prey

362 group sizes.

363

364

Aggregations are ubiquitous and part of many important life functions. Understanding

365 detectability and survival of aggregated prey will help us understand the adaptive mechanisms

366 driving distributions of prey organisms and how these interact with predators. Our study provides

367 insight into some adaptive reasons to aggregate in a system that is different from the usual visual

368 predator system. Many natural predators rely on olfactory cues but the consequences of this have

369 been relatively neglected by scientists, likely because of the dominant importance of vision to

370 humans. We demonstrate that aggregations are beneficial to prey avoiding non-specialist

371 olfactory foragers Since predation is a fundamental interaction structuring communities, changes

372 in the relative importance of vision and olfaction in prey detection (due to e.g. eutrophication)

373 could have far reaching implications ecologically. Our work provides a step towards improved

374 ability to predict these effects.

375

376 Acknowledgements

377 We wish to acknowledge Graeme Ruxton for valuable feedback on this manuscript. We

378 also wish to acknowledge Charlotte Leviston and Hugin Kárason Mortensen for their invaluable

379 help in gathering data for the laboratory and field studies respectively. Finally, we wish to

380 acknowledge Delbert Smee and Rachel Lasley-Rasher for helpful comments on our manuscript. 381 
383 Abrahams M V, Kattenfeld M. 1997. The role of turbidity as a constraint on predator-prey

384 interactions in aquatic environments. Behav. Ecol. Sociobiol. 40:169-174.

385 Andersson P, Löfstedt C, Hambäck PA. 2013. How insects sense olfactory patches - the spatial

386 scaling of olfactory information. Oikos 122:1009-1016.

387 Archard GA, Braithwaite VA. 2011. Variation in aggressive behaviour in the poeciliid fish

388 Brachyrhaphis episcopi: population and sex differences. Behav. Processes 86:52-7.

389 Brock VE, Riffenburgh RH. 1960. Fish schooling: a possible factor in reducing predation. ICES

390 J. Mar. Sci. 25:307-317.

391 Brodersen J, Malmquist HJ, Landkildehus F, Lauridsen TL, Amsinck SL, Bjerring R,

392 Søndergaard M, Johansson LS, Christoffersen KS, Jeppesen E. 2011. Short-and long term niche

393 segregation and individual specialization of brown trout (Salmo trutta) in species poor Faroese

394 lakes. Environ. Biol. Fishes.

395 Brown C, Laland KN. 2003. Social learning in fishes: a review. Fish Fish. 4:280-288.

396 Brown JS. 1999. Vigilance, patch use and habitat selection: Foraging under predation risk. Evol.

397 Ecol. Res. 1:49-71.

398 Cain ML. 1985. Random search by herbivorous insects: a simulation model. Ecology 66:876.

399 Chapman BB, Morrell LJ, Tosh CR, Krause J. 2010. Behavioural consequences of sensory

400 plasticity in guppies. Proc. R. Soc. B Biol. Sci. 277:1395-401.

401 Chesson P, Kuang JJ. 2008. The interaction between predation and competition. Nature 456:2354028.

403 Coombs S. 1999. Signal detection theory, lateral-line excitation patterns and prey capture

404 behaviour of mottled sculpin. Anim. Behav. 58:421-430.

405 Fay MP, Shaw PA. 2010. Exact and Asymptotic Weighted Logrank Tests for Interval Censored 406 Data: The interval R Package. J. Stat. Softw. 36:1-34.

407 Ferrari MCO, Lysak KR, Chivers DP. 2010. Turbidity as an ecological constraint on learned 408 predator recognition and generalization in a prey fish. Anim. Behav. 79:515-519.

409 Foster WA, Treherne JE. 1981. Evidence for the dilution effect in the selfish herd from fish 410 predation on a marine insect. Nature 293:466-467.

411 Frost AJ, Winrow-Giffen A, Ashley PJ, Sneddon LU. 2007. Plasticity in animal personality traits:

412 does prior experience alter the degree of boldness? Proc. R. Soc. B Biol. Sci. 274:333-9. 
413 Gentleman R, Vandal A. 2011. Icens: NPMLE for Censored and Truncated Data: R package

414 version 1.24.0.

415 Griffiths C, Richardson C. 2006. Chemically induced predator avoidance behaviour in the 416 burrowing bivalve Macoma balthica. J. Exp. Mar. Bio. Ecol. 331:91-98.

417 Harcourt JL, Biau S, Johnstone RA, Manica A. 2010. Boldness and information use in three418 spined sticklebacks. Ethology 116:440-447.

419 Ioannou CC, Bartumeus F, Krause J, Ruxton GD. 2011. Unified effects of aggregation reveal 420 larger prey groups take longer to find. Proc. R. Soc. B Biol. Sci. 278:2985-90.

421 Jackson AL, Brown S, Sherratt TN, Ruxton GD. 2005. The effects of group size, shape and 422 composition on ease of detection of cryptic prey. Behaviour 142:811-826.

Johannesen A, Dunn AM, Morrell LJ. 2012. Olfactory cue use by three-spined sticklebacks foraging in turbid water: prey detection or prey location? Anim. Behav. 84:151-158.

Kobak J, Kakareko T, Poznańska M. 2010. Changes in attachment strength and aggregation of 426 zebra mussel, Dreissena polymorpha in the presence of potential fish predators of various species 427 and size. Hydrobiologia 644:195-206.

428 Krause J, Ruxton GD. 2002. Living in Groups. Oxford University Press.

Leduc AOHC, Munday PL, Brown GE, Ferrari MCO. 2013. Effects of acidification on olfactorymediated behaviour in freshwater and marine ecosystems: a synthesis. Philos. Trans. R. Soc.

431 Lond. B. Biol. Sci. 368:20120447.

432 Long JD, Smalley GW, Barsby T, Anderson JT, Hay ME. 2007. Chemical cues induce consumer433 specific defenses in a bloom-forming marine phytoplankton. Proc. Natl. Acad. Sci. U. S. A. 434 104:10512-7.

435 Malmquist HJ, Ingimarsson F, Jóhannsdóttir EE, Ólafsson JS, Gíslason GM. 2002. Zoobenthos in 436 the Littoral and Profundal Zones of Four Faroese Lakes. Ann. Soc. Sci. Færoensis Suppl. Suppl. 437 36:79-93.

438 Monismith SG, Koseff JR, Thompson JK, O’Riordan CA, Nepf HM. 1990. A study of model 439 bivalve siphonal currents. Limnol. Oceanogr. 35:680-696.

440 Preisser EL, Orrock JL, Schmitz OJ. 2007. Predator hunting mode and habitat domain alter 441 nonconsumptive effects in predator-prey interactions. Ecology 88:2744-2751.

442 R Core Team. 2013. R: A language and environment for statistical computing. Vienna, Austria: R 443 Foundation for Statistical Computing.

444 Rasmussen JB, Downing JA. 1988. The spatial response of chironomid larvae to the predatory 445 leech Nephelopsis obscura. Am. Nat. 131:14. 
446 Reimer O, Tedengren M. 1997. Predator-induced changes in byssal attachment, aggregation and

447 migration in the blue mussel, Mytilus edulis. Mar. Freshw. Behav. Physiol. 30:251-266.

448 Riipi M, Alatalo R V, Lindström L, Mappes J. 2001. Multiple benefits of gregariousness cover 449 detectability costs in aposematic aggregations. Nature 413:512-4.

450 Roberts G. 1995. Salt-marsh Crustaceans, Gammarus duebeni and Palaemonetes varians as 451 Predators of Mosquito Larvae and Their Reaction to Bacillus thuringiensis subsp. israelensis. 452 Biocontrol Sci. Technol. 5:379-386.

453 Spence KW. 1937. Experimental studies of learning and the higher mental processes in infra454 human primates. Psychol. Bull. 34:806-850.

455 Sun J. 1996. A non-parametric test for interval-censored failure time data with application to 456 AIDS studies. Stat. Med. 15:1387-95.

457 Taylor RJ. 1977. The value of clumping to prey: experiments with a mammalian predator. 458 Oecologia 30:285-294.

459 Therneau TM, Grambsch PM. 2000. Modeling Survival Data: Extending the Cox Model. 460 London: Springer.

461 Therneau TM, Lumley T. 2011. survival: Survival analysis, including penalised likelihood: R 462 package version 2.36-5.

463 Thorpe WH. 1956. Learning and instinct in animals. Harvard University Press.

464 Treisman M. 1975. Predation and the evolution of gregariousness. I. Models for concealment and 465 evasion. Anim. Behav. 23:779-800.

466 Turesson H, Brönmark C. 2007. Predator-prey encounter rates in freshwater piscivores: effects of 467 prey density and water transparency. Oecologia 153:281-90.

468 Turnbull BW. 1976. The empirical distribution function with arbitrarily grouped, censored and 469 truncated data. J. R. Stat. Soc. 38:290-295.

470 Turner GF, Pitcher TJ. 1986. Attack abatement: a model for group protection by combined 471 avoidance and dilution. Am. Nat. 128:228-240.

472 Vollset KW, Bailey KM. 2011. Interplay of individual interactions and turbidity affects the 473 functional response of three-spined sticklebacks Gasterosteus aculeatus. J. Fish Biol. 78:1954-64.

474 Ward AJW, Thomas P, Hart PJB, Krause J. 2004. Correlates of boldness in three-spined 475 sticklebacks (Gasterosteus aculeatus). Behav. Ecol. Sociobiol. 55:561-568.

476 Webster DR, Weissburg MJ. 2009. The Hydrodynamics of Chemical Cues Among Aquatic 477 Organisms. Annu. Rev. Fluid Mech. 41:73-90. 
478 Webster MM, Laland KN. 2012. Social information, conformity and the opportunity costs paid 479 by foraging fish. Behav. Ecol. Sociobiol. 66:797-809.

480 Whitton TA, Jenkins SR, Richardson CA, Hiddink JG. 2012. Aggregated prey and predation 481 rates: Juvenile shore crabs (Carcinus maenas) foraging on post-larval cockles (Cerastoderma 482 edule). J. Exp. Mar. Bio. Ecol. 432-433:29-36.

483 Wilson ML, Weissburg MJ. 2012. Temporal and spatial sampling strategies maintain tracking 484 success of whelks to prey patches of differing distributions. Anim. Behav. 84:1323-1330.

485 Wootton RJ. 1976. The Biology of the Sticklebacks. Academic Press.

486 Wrona FJ, Dixon RWJ. 1991. Group size and predation risk: a field analysis of encounter and 487 dilution effects. Am. Nat. 137:186.

488 


\section{Figure 1}

Feeding station used in field

Figure 1. "Feeding station" after use in field trials. Cotton thread attached at the top assisted in positioning and retrieval of stations and to the right is an entrance hole with "doors" intact to ensure opening was not blocked by straying material. A similar opening is found on the opposite side of the station.

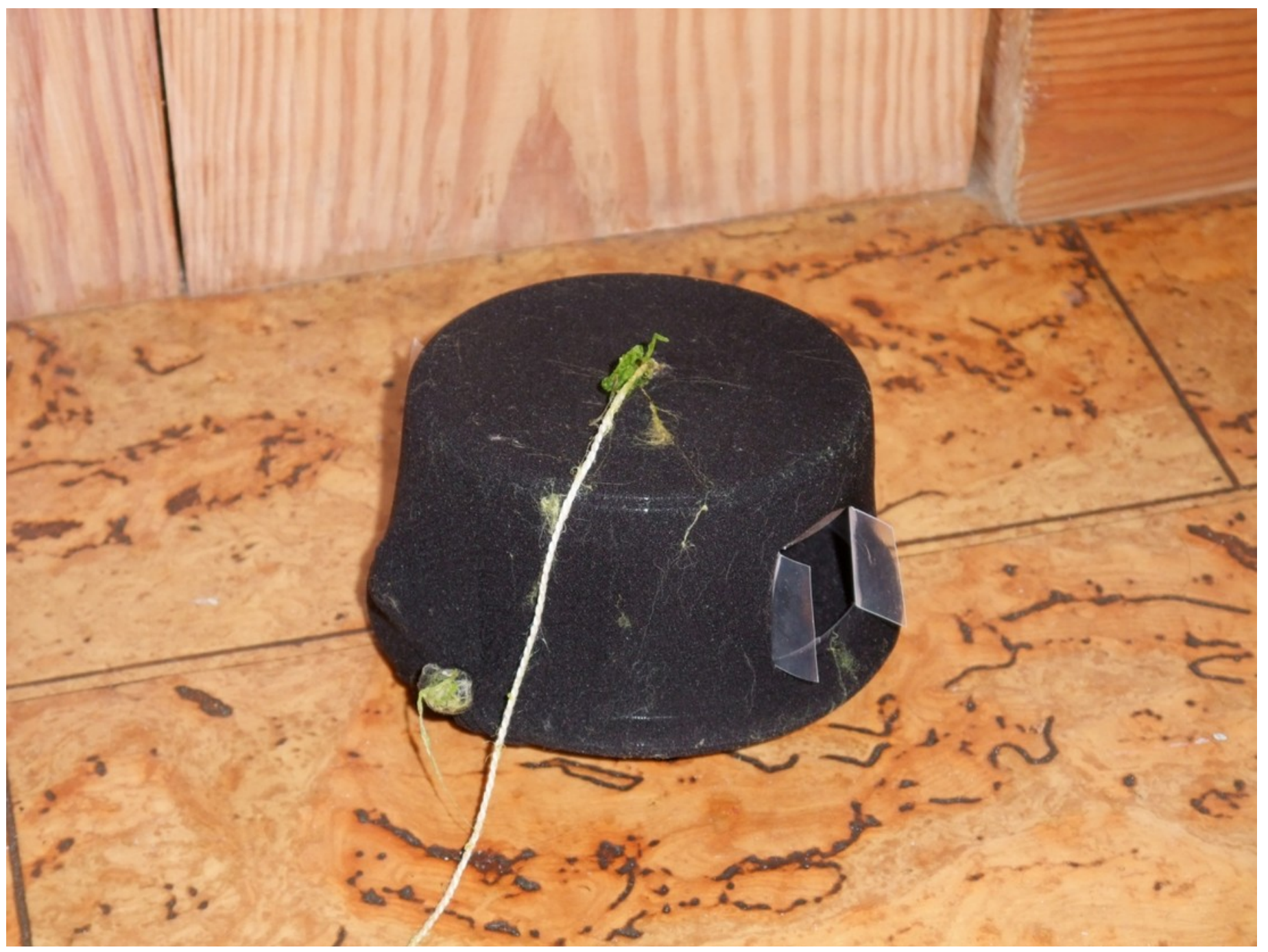




\section{Figure 2}

Overall prey survival in the laboratory

Figure 2. Kaplan-Meier survival curves for the four groups of prey. Crosses signify censored events where the observations for a particular trial ended before all prey were eaten. The curve for aggregated prey in turbid water shows a different pattern to the curves for the other three treatments.

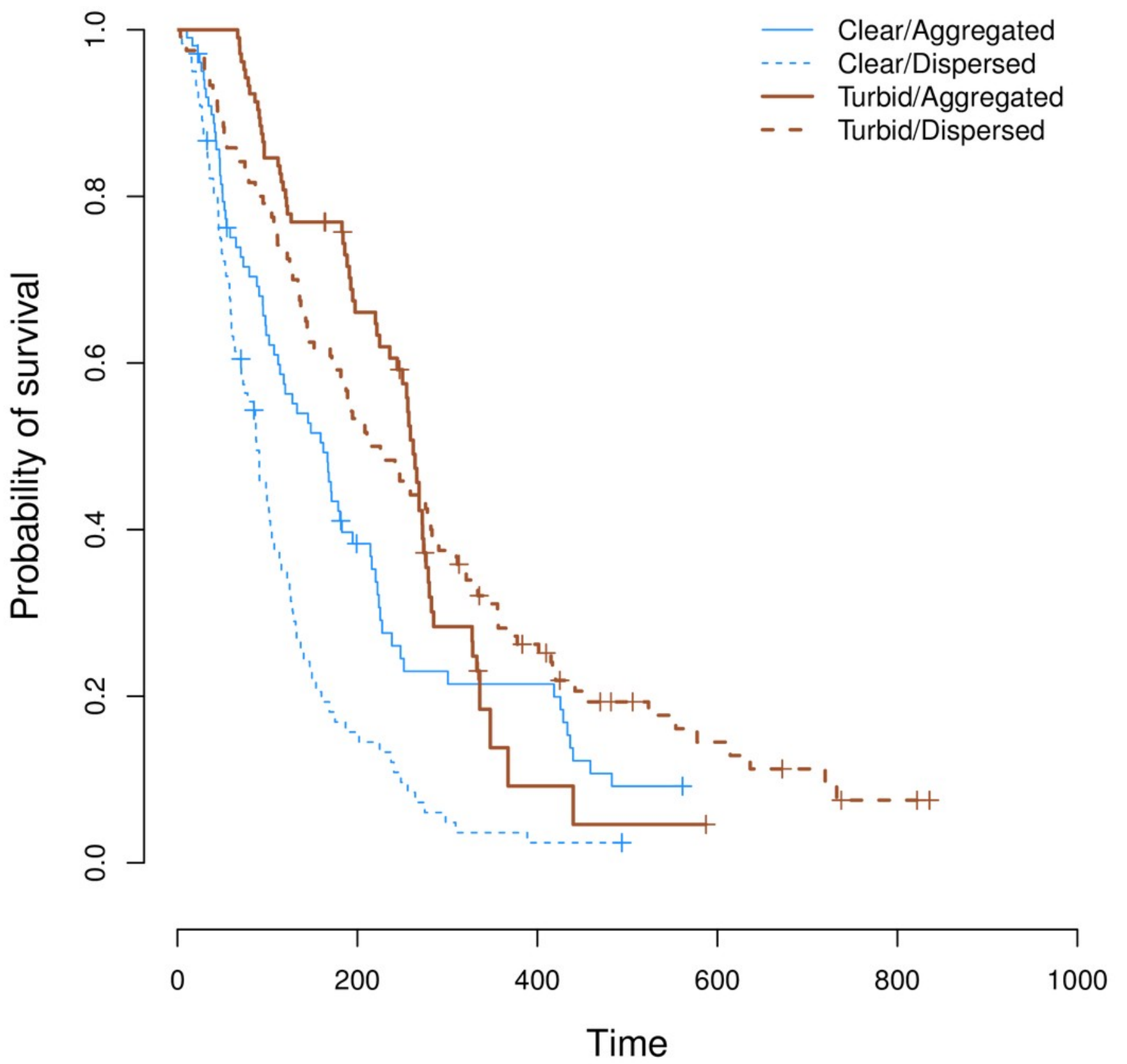




\section{Figure 3}

Survival on first prey in trial (a) and subsequent prey (b)

Figure 3. Kaplan-Meier curves for time to discovery of first (a) and subsequent (b) prey. Brown lines represent turbid water and blue lines clear water. Solid lines represent aggregated prey and dashes represent dispersed prey. In (b), the time axis was logged to improve clarity.
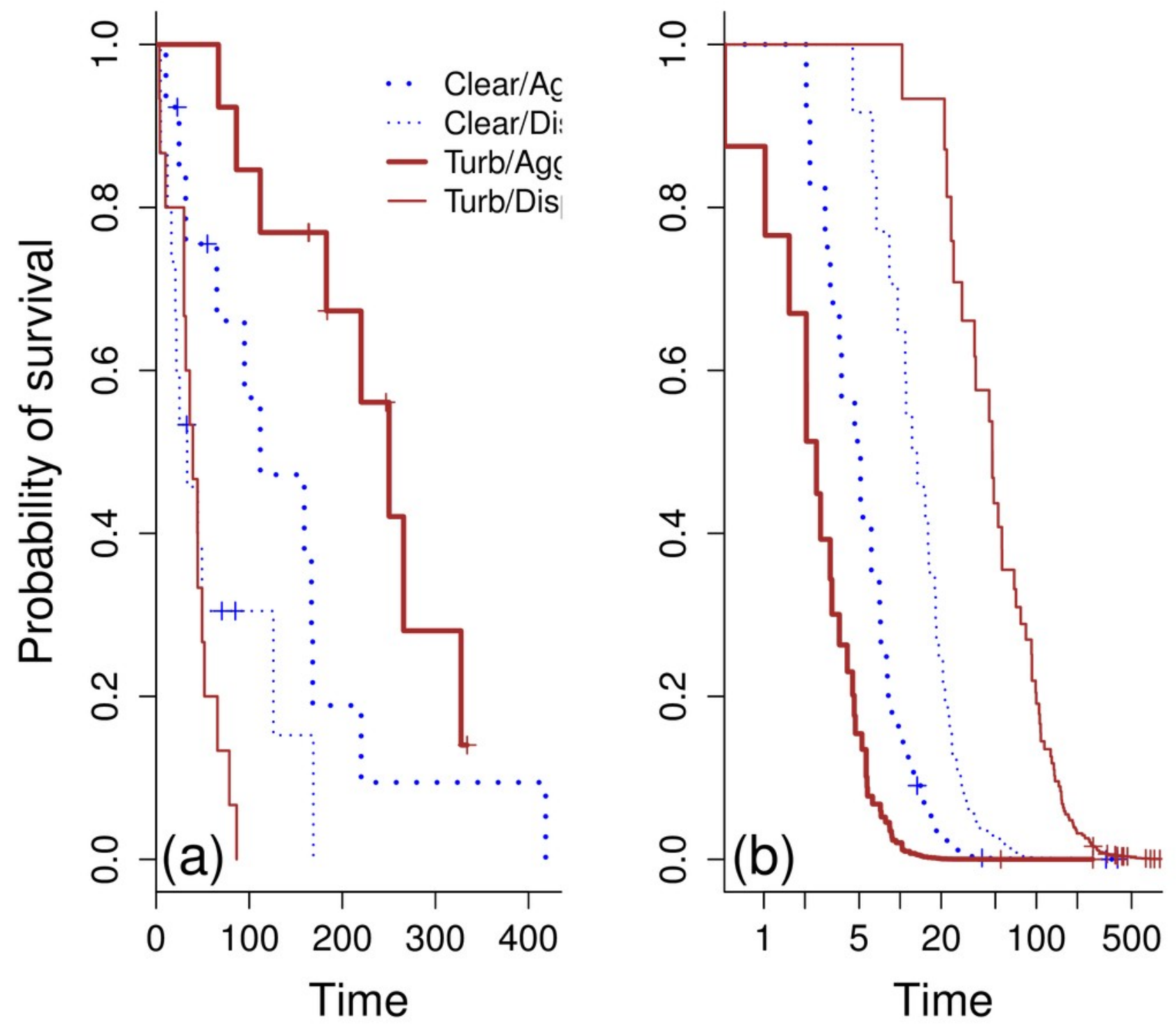


\section{Figure 4}

Field trial survival

Figure 4. Interval censored survival curves for the field data. Possible stepwise changes in survival lie within the shaded area for each curve. Aggregated: solid line, light shading, semidispersed: dashed line, medium shading, dispersed: dotted line, dark shading.

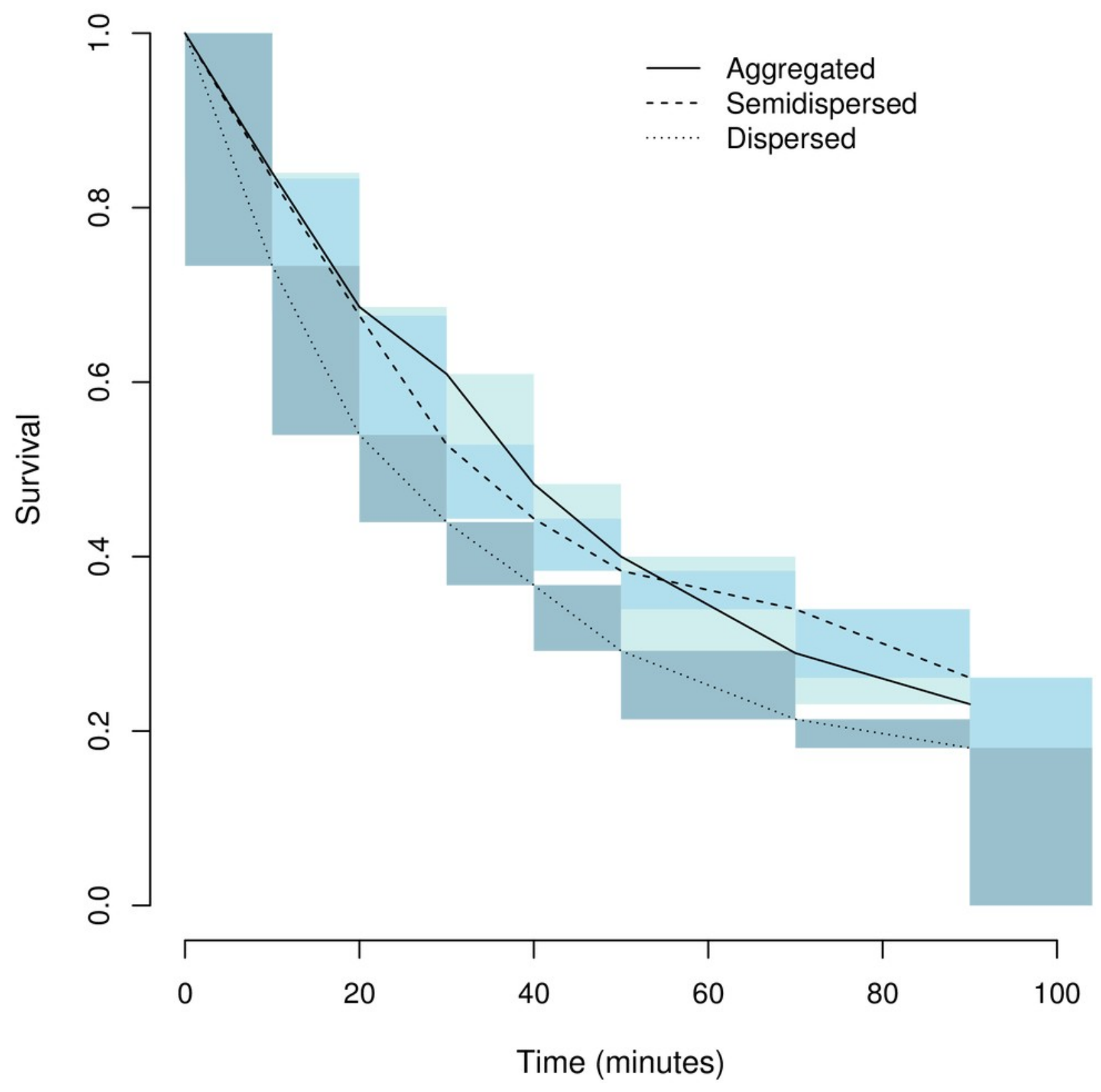

